\title{
Effectiveness of Reflexology in Prevention of Post-Operative Pain After General Surgery
}

\author{
Shweta Choudhary \\ Mahaveer Ayurvedic Medical College and Hospital, Meerut, India; \\ Choudhary Charan Singh University Meerut (UP), Meerut, India
}

\begin{abstract}
In this study, we tried to find out the efficacy of reflexology in prevention of post-operative pain. Different types of methods have been used for prevention of post-operative pain. Conventional Method-analgesia-diclofenac and pethidine non-conventional method-acupressure, acupuncture, and reflexology. The purpose of the paper is to find the efficacy of reflexology in patients with postoperative pain after general surgery. The method is that 60 adult patients of general surgery from The All India Institute of Medical Science over the period of 2001-2005. Patients were divided randomly into two groups: Group I: Reflexology group (foot reflexology and required quantity of standard drugs) and Group II: Control group (standard quantity of standard drugs). Standard drugs included: NSAID (Diclofenac) and Opioids (Pethidine and Fentany l). Pain score was measured by using a visual analog scale of 0-10. In Group I, pain was measured at the time scale of 0, 2, 6, and 24 hours, and additionally, 20 minutes prior to each hour. Twenty minutes is the time interval before and after therapy. 0 (zero hour). Is time which patient was shifted to recovery room. In Group II, pain score was measured at time intervals of 0, 2, 6, and 24 hours only. The result is that Group I showed a significant decrease and absolutely significance in pain scores and the requirement and quantity of drugs in Group I as compared to Group II. The discussion is that under the most circumstances pain causes, the greater amount of suffering. Particularly, after general surgery, the effect of foot reflexology causes a very significant reduction of pain score and pain killer in Group I in comparison with Group II in post-operative patients of general surgery.
\end{abstract}

Keywords: effectiveness of reflexology, prevention, post-operative pain, general surgery

\section{The Body of Paper}

Reflexology is one of the most miraculous means of utilizing a natural healing method for maintaining the body in a post-operative condition. Reflexology is a non-pharmaceutical intervention. The body's vital life force circulates along pathways with an estimated 800 points on the body (see Figure 1). It is not necessary to know all of these points since the hand as well as the feet contain "reflex buttons", which are connected to all organs and glands. When these reflex centers are stimulated, they instantly send a surge of new vigor to the part of the body they are connected to and with no side effects.

Shweta Choudhary, Ph.D., AIIMS New Delhi, assistant professor, Mahaveer Ayurvedic Medical College and Hospital; Choudhary Charan Singh University Meerut (UP), Ministry of Health Ayush and CCIM. 


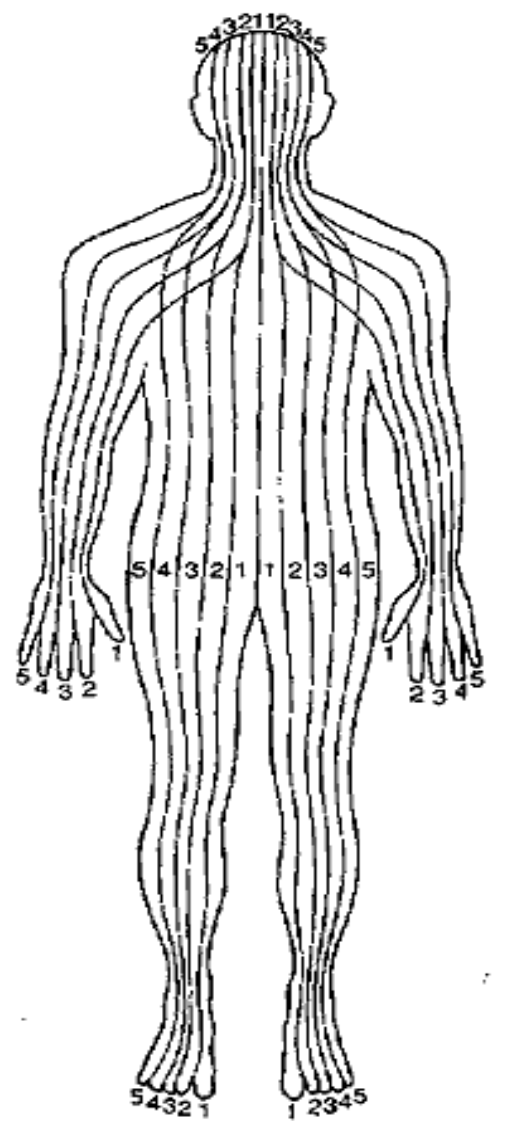

Figure 1. Body representing the various zone.

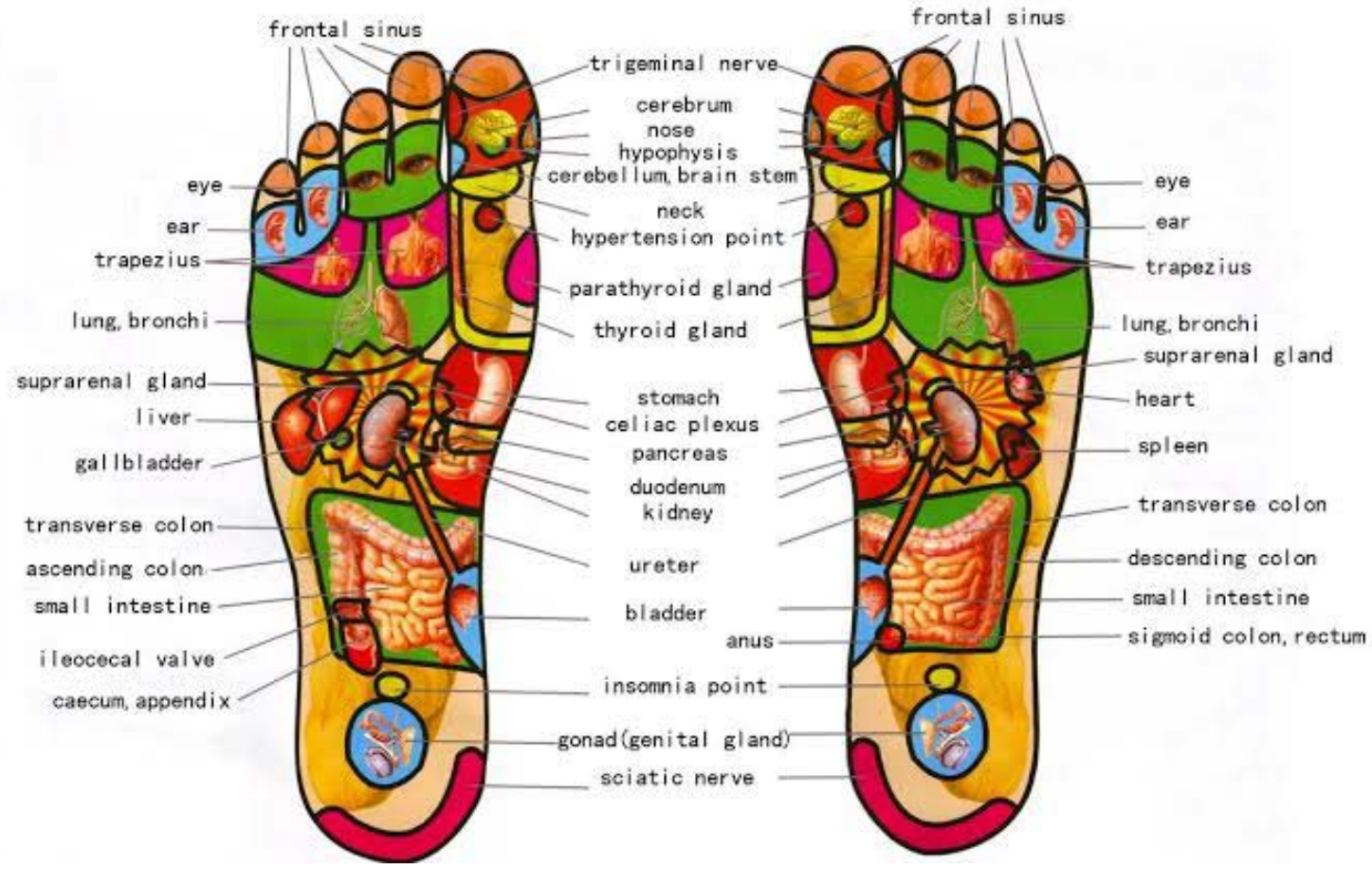

Figure 2. The foot map. 


\section{The Use of Reflexology has Increased in Medical Care}

Recent reports include usage in birthing. OBGYN care, post surgical care, ICU, and patient support. The International Institute of Reflexology clearly states that it does not make any medical claims.

Theory of Reflexology. There are over 7,200 nerve endings in each foot, which have an extensive interconnection with the central nervous system. These nerve endings are part of our sensory apparatus in which they sense pain and pressure, hot and cold, etc. Reflexology stimulates or fine-tunes this sensory apparatus and its neural pathways. Stress patterns are also manifested on the feet. There are many theories of reflexology, some of which are explained here.

Applied Theory. The foot reflects the body's response to the stresses of gravity and movement.

Blood and nerve supply theory. When muscles become tense, they press on the arteries causing sluggishness in circulation. This results in toxins in the blood, which would normally be excreted. At these deposits, needle shaped crystals settle in the extremities of the hands and feet. It is believed that these deposits interrupt some nerve impulses and cause dysfunction in the blood circulation. Reflexology applies pressure to break down the crystals and release them through the excretory systems.

Pain. Post-operative pain is attributed to the cutting of pain fibers or irritation of pain nerve endings.

\section{Methods Used in Prevention of Post-Operative Pain}

1. Conventional method-Painkillers, such as NSAID (Diclofenac) and opioids (Pethidine and Fentany l);

2. Non-conventional method-Acupressure, acupuncture, and reflexology.

Method: Sixty adult patients were randomly divided into Group I (Reflexology group) and Group II (Control group).

Step I: Reflexology group (foot reflexology plrs the required quantity of standard drugs), $N=32$ (12 males and 20 females);

Step II: Control group (standard quantity of standard drugs), $N=28$ (12 males and 16 females).

Standard pain killer's reds: NSAID (Diclofenac) and opioids (Pethidine and Fentany l).

Pains measurements were used in this study:

1. Measurement of quantity and requirement of painkillers;

2. Measurement of pain score.

Score was done at four different time intervals:

1. Group I-Pain score was measured 0, 2, 6, and 24 hours, and 0 hours-20 minutes, 2 hours-20 minutes, 6 hours-20 minutes, and 24-2 minutes;

2. Group II-Pain score was measured at 0, 2, 6, and 24 hours.

Zero hours as defined as the time patient was moved to recovery room.

Twenty minutes is the time before and after reflexology therapy.

It was noted that there was a decrease in the requirement and quantity of painkillers in the reflexology Group I compared with the control Group II.

Pain was monitored on a visual analog scale (VAS) of 0 to 10 , with $0-5=$ Mild pain, $5=$ Moderate pain, and 5-10 = Severe pain.

\section{Pain Score}

Visual analog scale has been used for measurement of pain. 


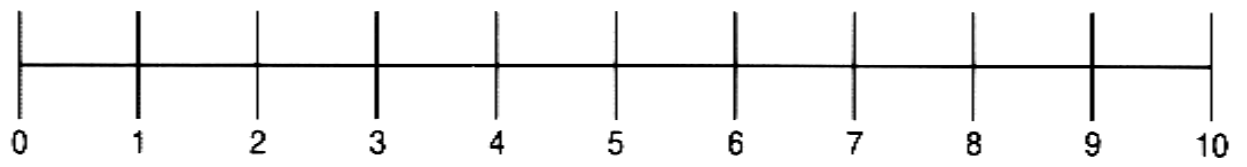

$0-5=$ Mild pain;

5 = Moderate pain;

5-10 = Severe pain

In Group I (Reflexology group), post operated pain has been monitored in hours and minutes both at the time interval of 0 hours, 0-20 minutes, 2 hours, 2 hour- 20 minutes, 6 hours, 6 hours- 20 minutes, 24 hours, and 24 hours-20 minutes.

Group I received foot reflexology for 15-20 minutes. Sessions began with reflexology techniques, and thumb (thumb walking and dig and back up), and finger (finger walking and finger rotary pressure) working techniques. Areas reflexes were specific to type of surgery performed and the related areas of pain.

\section{Results}

This study shows a decrease of the quantity of painkillers in Group I to less than $50 \%$ as compared to Group II (see Table 1).

Table 1

Comparison of Quantity of Painkillers in Group I and Group II

\begin{tabular}{lllll}
\hline Time interval & 0 hour & 2 hours & 6 hours & 24 hours \\
\hline Group I & $65.5 \%$ & $19.5 \%$ & $75 \%$ & $65.5 \%$ \\
Group II & $100 \%$ & $85 \%$ & $100 \%$ & $100 \%$ \\
& $P=0.001$ & $P=0.001$ & $P=0.005$ & $P=0.002$ \\
\hline
\end{tabular}

Statistical analysis was done by applying the Fischer exact test (Chi-Square test).

Table 2

Comparison of Pain Score in Group I and Group II

\begin{tabular}{lllll}
\hline Time interval & 0 hour & 2 hours & 6 hours & 24 hours \\
\hline Group I & $0.25 \pm 1.646$ & $4.906 \pm 1.201$ & $3.813 \pm 0.5748$ & $2.28 \pm 0.683^{*}$ \\
Group II & $6.393 \pm 1.397$ & $4.43 \pm 8.00$ & $4.43 \pm 8.00$ & $3.143 \pm 0.5$ \\
& $P=0.007$ & $P=0.026$ & $P=0.009$ & $P=0.000$ \\
\hline
\end{tabular}

\section{Footnotes}

Pain: Post-operative pain is attributed to the cutting of pain fibers or irritation of pain nerve endings.

\section{Gating Theory}

Specific neural pathway for specific pain fibers (A delta nerve fibers) travel through the spin thalamic tract towards the central nervous system. When touch and pressure is applied on specific reflex point, it would activate slow conducting $C$ fibers that take the same pathway thereby inhibit the path of A delta nerve fibers and block the pain.

\section{Reflexology}

Reflexology is the act of applying pressure on the corresponding point of disorder organ/area of the body to the feet and hands with specific thumb. Finger and hand technique without using oil, lotion, or cream, use 
telecom powder. The physiological changes achieved with the application of pressure are based on the neurological relationship that exists between the skin and the nervous system. Whereas, a therapeutic effect can be achieved by stimulation at a distance from the arca where the pressure is applied. Reflexology believes that the body is reiterated or mirrored on the feet and hands and works within a zonal system, as introduced by Dr. William Fitzgerald. According to the zone theory, the body is divided into 10 equal longitudinal zones (five on the left side and five on the right side) running through the body from the top of the head to the tips of the toes. If there is congestion in any part of the body, the corresponding zone is affected. Using this theory, we apply direct pressure to any part of the affected zone to stimulate the entire zone. Dr. Riley supported the zone theory and his assistant, Eunice Ingham plotted the reflexes of all the body areas onto the feet, thus creating the foot map.

The study of reflexology is based on anatomy and physiology of the human body. The principle of reflexology is founded on the understanding of how the nerves work and what they mean to the human body.

Under most circumstances pain causes the greater amount of suffering, particularly after major surgeries.

The specific area of central nervous system to which afferent nerve fiber pass determines the type of sensation. For example, if a pain nerve fiber is stimulated by heat, cold, touch, and pressure, the individual will experience only pain

\section{Gating Theory}

According to this theory, pain signals pass through a number of traffic "gates" as they move from the area of injury upwards through the spinal cord to the brain. Like a road or highway, these nerves can handle only a limited number of nerve signals at one time. The pain signals travel slowly. We can generate $\mathrm{C}$ fibers through use of reflexology by applying pressure on a specific reflex point.

Reflexology generates competing stimulus of $\mathrm{C}$ fibers and effectively blocks the slow pain signals from reading the brain, blocking the pain pathway. The gating theory says that pain impulse can be blocked in the spinal cord by habiting signals coming from touch nerve fibers due to this relief in pain.

\section{Reflex Conditioning}

1. Stimulus-Information is sent from the foot to the brain;

2. Evaluation-The brain analyzes the information;

3. Response-After brain response to the recent information by sending instruction to the entire body.

About how to adapt Transduction. It is a process by which one form of energy (the stimuli) is changed to another form of energy (electro-chemical energy of nerve impulse). The stimuli when applied to the receptor, brings about a change potential of the plasma membrane of the nerve ending. Since this process takes place in the receptor, it is referred to as the receptor potential. If the receptor potential is large enough, it generates an action potential Impulse conduction is simply the movement of action potentials along a nerve cell.

It has been observed in other studies in pre-operative insertion of intradermal needles at visceral associated BI acu points reduces postoperative pain scores, opioid requirement, opioid-related side effect, and adrenal responses induced by surgical stress in patients undergoing upper and lower abdominal surgery. Post operative pain management aims not only to decrease pain intensity, but also to increase patient comfort and to improve postoperative outcome. Better pain control is achieved through a multimodal combination of regional analgesic techniques and systemic administration of analgesic agents. To guarantee uneventful follow-up and unnecessary. 
Prolongation of hospital stay, it is important to avoid side-effects of analgesic agents, especially those of opioids, which are dose-related by decreasing opioid demand through combination with non-opioid agents. Epidural analgesia not only has the advantage of providing potent and effective analgesia, but also of hastening recovery of bowel function and facilitating physiotherapy and rehabilitation. Unfortunately, a reduction in postoperative morbidity and mortality by epidural analgesia has not actually been demonstrated. Inclusion of postoperative pain treatment in a multimodal approach of patient rehabilitation may improve recovery and shorten hospital stay. Effective treatment of postoperative pain is also likely to prevent chronic pain syndrome after surgery, but further studies are needed to support this hypothesis. So, in this research study, we tried out the effectiveness of reflexology for prevention of post-operative pain and also reduce the quantity of pain killer or analgesia after general surgery.

\section{Comparison of pain in group I (Reflexology group) and in group II (Control group)}

\begin{tabular}{|c|c|c|c|}
\hline S.No. & GP $(\mathrm{I})$ Mean \pm SD & GP (2) Mean \pm SD & Pvalue \\
\hline 1. & $5.25 \pm 1.646$ & $6.393 \pm 1.397$ & .007 \\
\hline 2. & $4.906 \pm 1.201$ & & .026 \\
\hline 3. & $3.813 \pm 1.5748$ & $4.43 \pm 1$ & .009 \\
\hline 4. & $2.28 \pm .683$ & $3.143 \pm .5$ & .800 \\
\hline
\end{tabular}

The result shows that pain score is less in group-I in comparison of group-II and the all results is significant.

*An absolutely significant decrease of pain score in Group I as compared to Group II. Statistical analysis was done by applying the " $T$ ” test.

Table 3

Comparison of Pain Score in Reflexology Group I Before and After Reflexology Therapy

\begin{tabular}{lllll}
\hline Time interval & 0 hour & 2 hours & 6 hours & 24 hours \\
Before therapy & $5.25 \pm 1.65$ & $4.91 \pm 1.20$ & $0.81 \pm 1.57$ & $2.28 \pm 0.68$ \\
After therapy & $5.28 \pm 1.42^{*}$ & $3.91 \pm 1.20^{* *}$ & $3.06 \pm 1.46$ & $1.59 \pm 0.084^{* *}$ \\
& $P=0.927$ & $P=0.000$ & $P=0.007$ & $P=0.000$ \\
\hline
\end{tabular}

Notes. *A non-significant decrease of pain score in Group I after reflexology therapy;

**An absolutely significant decrease of pain after reflexology therapy. 


\section{Comparison of pain in group-I in hours and minutes}

\begin{tabular}{|c|c|c|c|}
\hline & Mean & $\pm \mathrm{SD}$ & P value \\
\hline $\begin{array}{l}\text { 1. P 0h } \\
\text { h } 20 \mathrm{~m}\end{array}$ & $\begin{array}{l}5.25 \\
5.28\end{array}$ & $\begin{array}{l} \pm 1.65 \\
\pm 1.42\end{array}$ & .927 \\
\hline $\begin{array}{l}\text { 2. }{ }^{\mathrm{P} 2 \mathrm{~h}} \\
\mathrm{~h} 20 \mathrm{~m}\end{array}$ & $\begin{array}{l}4.91 \\
3.91 \\
\end{array}$ & $\begin{array}{l} \pm 1.20 \\
\pm .96 \\
\end{array}$ & .000 \\
\hline $\begin{array}{l}\text { P } 6 \mathrm{~h} \\
\text { P } 6 \mathrm{~h} 20 \mathrm{~m}\end{array}$ & $\begin{array}{l}3.81 \\
3.06\end{array}$ & $\begin{array}{l} \pm 1.57 \\
\pm 1.46\end{array}$ & .007 \\
\hline $\begin{array}{l}\text { P } 24 \mathrm{~h} \\
\text { P } 24 \mathrm{~h} 20 \mathrm{~m}\end{array}$ & 2.28 & $\begin{array}{l} \pm .68 \\
\pm .84\end{array}$ & .000 \\
\hline
\end{tabular}
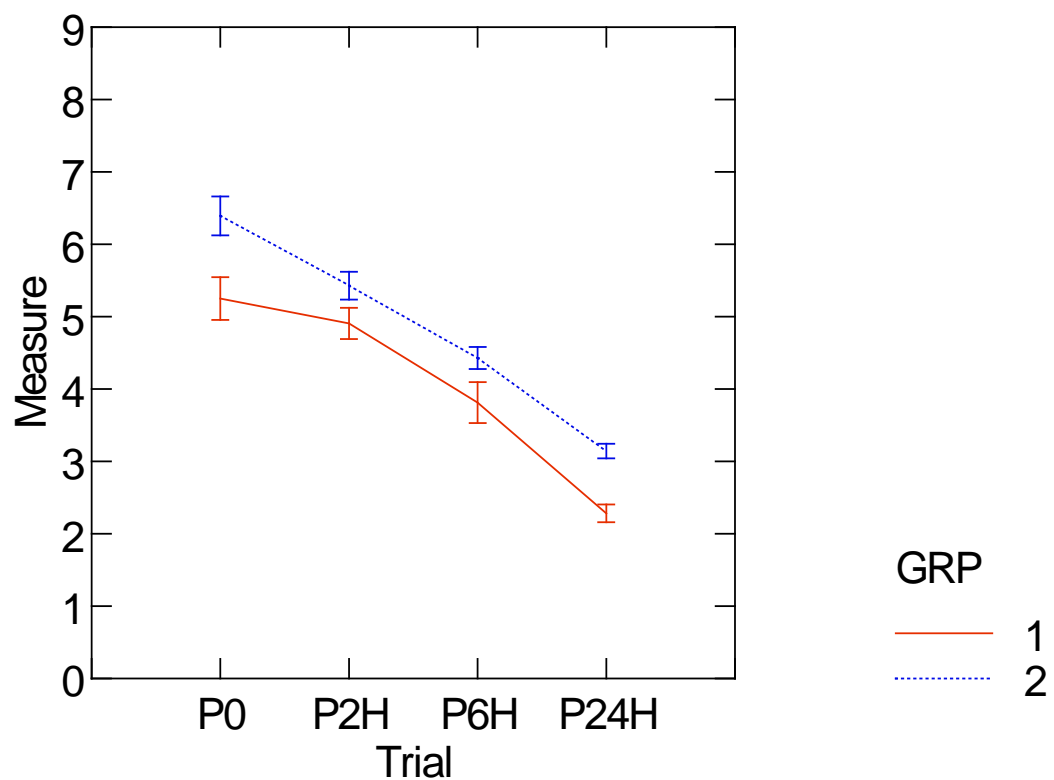

\section{References}

Broekema, A. A., Gielen, M. J. M., \& Hennis, P. J. (1996). Postoperative analgesia with continuous epidural sufentanil and bupivacaine: A prospective study in 614 patients. Anesth Analg, 82, 754-759.

Brown, D. L., \& Rone, D. K. (1994). Altered reactivity of isolated segmental lumbar arteries of dogs following exposure to ethanol and phenol. Pain, 56, 139-143.

Camu, F., \& Debucquoy, F. (1991). Alfentanil infusion for postoperative pain: A case comparison of epidural and intravenous routes. Anaesthesiology, 75, 171-178.

Caraceni, A., \& Portinoy, R. K. (1996). Pain management in patients with pancreatic carcinoma. Cancer, 78, 639-653. 
Dale, R. A. (1984). The principles and systems of micro-acupuncture. Int'I Journal of Chinese Medicine, 1, 15-42.

Dundee, J. W., Mioholl, R. M., \& Mkoore, J. (1962). Studies of drugs given before anesthesia. British Journal of Anesthesia, 84, 527.

Dundee, J. W., Moore, J., \& Clarke, R. S. J. (1984). Studies of drugs given before anesthesia. V. Pethidine 100 mgs Alone and With Atropine or Hyoscine Him is of Anesthesia, 36, 703-710.

Fujita, Y. (1993). CT-guided neurolyic splachnic nerve blook with alcohol. Pain, 55, 363-366.

Goweri, M., \& Jane, M. G. (2000, June). Forest gate, London, England: The effects of reflexology on labour outcome. L. Grealish, A. Lomasney and B. Whiteman (Eds.), Foot massage: A nursing intervention to modify the distressing symptoms of pain and nausea in patients hospitalized with cancer. Cancer Nurse, 23(3), 237-243. (Online review: "Reflexology Used for Cancer Patients, Internet Health Library, October 11, 2000)

Kehlet, H. (1989). Post-operative pain: American college of surgeons, care of the surgical patient. Committee on Pre- and Post-Operative Care New Ytific American Medicine, 1, 3-12.

Kesserling, A. (1994). Fussrels zone massage. Schweiz medwon/chenschr suppi (Switzerland), 62, 88-93.

Kesselring, A. (1999, February 6). Forsch Komplementarmed. Foot Reflexology: A Clinical Study (Suppl.), 1, 38-40.

Kevin, M., \& Kunz, B. (2000, August). Vkunz(e) reflexion journal. kunz and Kunz.

Martelete, M., \& Flori A. M. (1985). Comparative study of the analgesic effect of transcutaneous nerve stimulation (TNS): Electro acupuncture (E.A.) as meperidine in the treatment of peroprative pain. Acupunct Electrother Res., 10, 183-193.

Naoki, K. M. D., Hashimoto, H., Sato, Y, \& Sessleor, D. (2001, August). Preoperative intradermal acupunture reduced postoperative pain, nausea and vomiting analgesia requirement and sympathodermal response. Anaesthesiology, 95(2).

National Institute of Health. (1987). The integrated approach to the management of pain. J. Pain Symptom Management, 2, 35-44.

Oden, R. (1989). Acute post-operative pain: Incidence, severity, and the etiology of inadequate treatment. Anesth. Clin North. Am 7, 1-15.

Public Health Service Agency for Health Care Policy and Research. (1992, February). Acute pain management: Operative or medical procedure and trauma —Clinical practice guideline. Washington, DC: US Dept. of Health and Human Services. 